\title{
Patient's knowledge and awareness towards dental implants in young individuals of Ghaziabad district- A cross sectional study
}

\author{
Kunal Gaurav Seth ${ }^{1, *}$, Bhavana Sharma ${ }^{2}$, Nikhil Sharma ${ }^{3}$, Shubhra Vaish ${ }^{4}$, Mallika Sethi ${ }^{5}$ \\ ${ }^{1,2}$ Post Graduate, ${ }^{3}$ Professor and HOD, ${ }^{4}$ Professor, ${ }^{5}$ Associate Professor, Dept. of Periodontology and Oral Implantology, I.T.S \\ Centre for Dental Studies and Research, Ghaziabad, Uttar Pradesh, India
}

*Corresponding Author:

Email: kunal1026@gmail.com

\begin{abstract}
Aim: The aim of the study was to assess the knowledge and awareness towards dental implants in young individuals of Ghaziabad district.

Materials and Methods: A cross sectional survey of 150 individuals was done using a structured validated questionnaire among young individuals of 21-30 years.

Results: The results of this study indicated that $12 \%$ of the subjects knew about dental implants. The subjects friends and relatives were main source of information about dental implants for $8.7 \%$ and dentists were the secondary source for $2.7 \%$. $100 \%$ of the subjects wanted to know more about implants. Lack of knowledge was the major factor in preventing patients from choosing dental implants and high cost was also found to be a major deterrent factor.

Conclusion: This study showed that young individuals in Ghaziabad have limited awareness about dental implants. Awareness among youngsters is required that can help in eliminating any negative image that may have been caused due to lack of adequate information. It is also concluded that various efforts should be made to lower the cost of implants so that they can be made affordable to all who are in need of it.
\end{abstract}

Keywords: Knowledge, Awareness, Dental implants.

\section{Introduction}

The face is considered as a window into one's personality and the teeth plays an important role in the maintenance of a positive selfimage. ${ }^{1}$ Tooth loss can adversely affect an individual's life. It has been found to have an emotional impact affecting one's self confidence, food habits, esthetics, function and personal as well as social life. ${ }^{1,2}$

In cases of completely missing teeth in maxillary and mandibular arches, removable partial denture, fixed partial dentures and complete dentures are the treatment choices. ${ }^{1}$ Rapid research and advancement in the field of dental implants helped the need to replace lost teeth with a near-natural successor. ${ }^{1,3}$

Dental implant is an artificial root which is inserted surgically into the jawbone to support a single tooth replacement (crown), fixed partial or complete denture or maxillofacial prostheses. ${ }^{1,4}$ Dental implant is an ideal option in people with good oral health who have lost a tooth/ teeth due to any kind of injury, failed endodontic treatments etc. Such cases are most commonly seen in young individuals and replacing these missing teeth with dental implants is an ideal treatment option. ${ }^{1,4}$

Implant supported rehabilitations are esthetically more attractive than removable prostheses. Studies have shown significant improvement in patient's attitude towards their dental health after treatment with dental implant. ${ }^{1,5}$

Number of dental implants placed annually worldwide has been approximated to be close to 1 million. ${ }^{6,7}$ However the awareness regarding dental implant treatment is considerably less especially in developing countries like India, where people have low levels of literacy and less awareness about overall dental health. ${ }^{7,8}$ Also the financial cost is always a point of doubt in the people who are aware about implants. ${ }^{9}$

A recent study showed that public media such as journals and television have given some negative reports about dental implants. ${ }^{10}$ In a professional society it is necessary that information given should be true. Awareness and knowledge about dental implants can help persons to evaluate their expectations from a treatment which can be obtained in reality. ${ }^{10,11}$

Hence, in order to promote oral health and improved overall quality of life of patients with tooth loss, the present questionnaire study was conducted with an aim to assess the sources, level of awareness and need for information about dental implants in young individuals of Ghaziabad district, Uttar Pradesh, India.

\section{Materials and Methods}

A descriptive cross sectional study was done among 150 young individuals of Ghaziabad district, Uttar Pradesh after clearance from the Institutional ethical board.

Persons in the age group of 18-30 years from Ghaziabad District were included.

A random sampling method with convenient sample was taken. The data was collected using selfexplanatory questionnaire based on previous studies. ${ }^{12-}$ 1414 questions were chosen to assess patients awareness, acceptance and perceived cost of dental implants. The questionnaire also records the 
demographic details of the participants as well as the responses to questions.

Initially a pilot study was done in 20 subjects to know the efficiency of the questionnaire and a sample size of minimum 150 participants was finalized. (Fig. 1) The questions in the questionnaire dealt with the following aspects.

1. Level of information about dental implants.
2. Level of acceptance of dental implants used as a treatment option in comparison to other conventional treatment modalities.

3. Dental implant information sources.

The questionnaires were given to the participants in the engineering college premises. All the participants were informed regarding the objectives and aims of the study.
1. Do you know missing teeth should be replaced?
a. Yes, always
b. Yes, if gap is visible
c. No

2. What alternatives for replacing teeth do you know?
a. Implant supported reconstructions
b. Removable Prostheses
c. Fixed partial dentures
d. None

3. Which tooth replacement has more advantages in your view?
a. Non removable
b. Removable

4. Are you aware of dental implant treatment as an alternative for missing teeth?
a. Yes
b. No

5. If you heard of dental implants from where you heard about it?
a. Newspapers/magazines
b. Television/Radio
c. Internet
d. Dentists
e. Relatives

6. Would you like to know more about implants?
a. Yes
b. No

7. Where in the jaw do you think implants are placed?
a. In the jawbone
b. In the gums
c. Do not know

8. How well informed do you feel about implants?
a. Very well
b. Well
c. Poorly
d. Not at all

9. Mode of education preferred
a. Visual
b. Model
c. Education template

10. How long do you think an implant lasts?
a. Up to 5 years
b. Up to 10 years
c. Up to 20 years
d. For a lifetime

11. What do you think of the treatment charges involved in this procedure?
a. Affordable
b. Non affordable

12. Up to which amount are you prepared to pay as a payment for implant?
a. $<4000$
b. $<8000$
c. $<10000$
d. No idea

13. What do you think are the limitations of dental implant therapy?
a. High cost
b. Lack of knowledge
c. Need of surgery
d. Long treatment time

14. Are you willing to undergo an implant treatment if needed?
a. Yes
b. No
c. Not sure

Fig. 1: Questionnaire on knowledge and awareness about dental implants 


\section{Data Analysis}

A master chart was created in Microsoft Excel 2016 for analysis of data. A statistical software, SPSS version 21 was used for data analysis. After that descriptive statistics were obtained and frequency distribution, means, standard deviation were calculated using Student's t-test and ANOVA test was applied.

\section{Results}

A total of 150 people participated in the study out of which 92 were males $(61.3 \%)$ and 58 were females $(38.7 \%)$.

When asked about if missing teeth should be replaced, $2.7 \%$ participants said yes and $95.3 \%$ participants said yes only when gap is visible and $2 \%$ participants said no to this question.

When asked about alternatives to replace missing teeth, 74\% participants know about fixed prostheses and $25.3 \%$ people know about removable prostheses and when asked about dental implant as an alternative for missing teeth only $12 \%$ (Fig. 2) know about the treatment modality and when same people asked about where they heard about the modality, dentists $(2.7 \%)$ and relatives $(8.7 \%)$ were the main source of information regarding dental implants.

When asked if they want to know more about the implants $100 \%$ respondents said yes to this question. When asked about mode of education preferred for seeking knowledge about implants $83.3 \%$ participants asked about visual mode and $16.7 \%$ participants told that they rely on models for more knowledge about implants.

When asked about willingness to undergo implant treatment if needed $22.7 \%$ respondents said yes to this question and $0.7 \%$ said no and $76.7 \%$ were not sure to this question. (Fig. 3)

When asked about limitations for undergoing this treatment option high cost (13\%) and lack of knowledge $(87 \%)$ are the main constraints for undergoing this treatment modality. (Fig. 4)

Fig. 2: Awareness about dental implant as an option for missing teeth

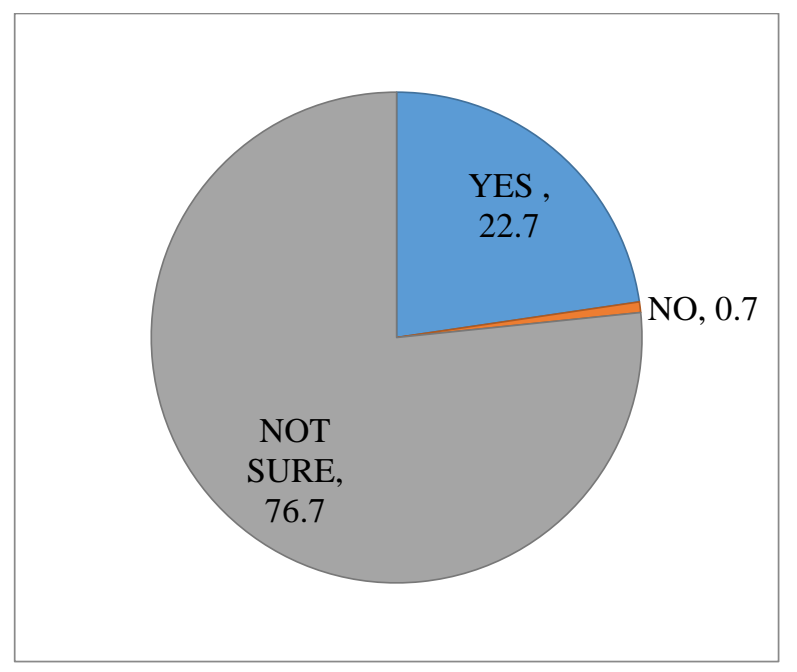

Fig. 3: Willingness to undergo implant treatment if needed 


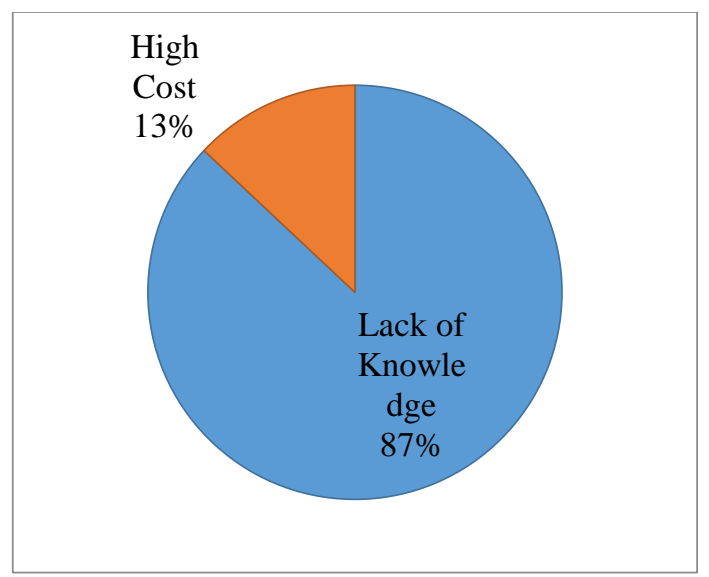

Fig. 4: Constraints in getting dental implants

\section{Discussion}

Missing teeth replacement by means of implant supported prosthesis for esthetic and functional rehabilitation has emerged to be an established and immensely used treatment modality in the arena of dentistry.

The present survey gives information about individuals knowledge and attitude towards dental implants in replacing missing teeth as a treatment option. One million dental implants are being inserted each year, worldwide. ${ }^{12}$ However, information that is available to the patients about the procedure and its success, is often very less. This problem is more prevalent in developing nations.

The study group individuals had a high level of education in the present study. $100 \%$ were college graduates.

In the present study, awareness regarding implants were among $12 \%$ participants which was very less than other studies done by Zimmer et al (1992), ${ }^{6}$ Berge (2000), ${ }^{15}$ and Tepper et al. (2003) ${ }^{11}$ who reported awareness level as $77,70.1$ and $72 \%$, respectively which could be due to low level of education in the study sample.

This survey found that, the main source of information about dental implant were the relatives and friends, followed by the dentists, newspaper and magazines, and lastly the internet which is in accordance with a study done by Al Johany et al (2010). ${ }^{5}$ The results are different than what were published before. A survey made by Zimmer et al. ${ }^{6}$, concluded that media was found to be the main source of information regarding dental implants, and the dentists were the source for such information is not more than $17 \%$ in most of the cases. Berge $(2000)^{15}$ and Best $(1993)^{16}$ found that the media was the main source of information; whereas dentists played a secondary role. In a study done by Akagawa et al. $(1988)^{17}$ they concluded that, dentists provided less than $20 \%$ of the information. Generally patients were not interested in having removable prostheses as the treatment in replacing missing teeth, which confirms that most patients prefer fixed prostheses in replacing missing teeth. This result was in accordance with those done by Tepper et $\mathrm{al}^{11}$ and Zimmer et al. ${ }^{6}$

When questions were asked regarding constraints in implant placement, majority of them mentioned high cost and lack of knowledge as the major factor. Similar results were obtained in most of the previous studies done by Kaurani $\mathrm{P}$ et al (2010), ${ }^{18}$ Johany SA et al (2010), ${ }^{5}$ Tepper et al (2003), ${ }^{11}$ Kent $(1992)^{19}$ and Zimmer et al (1992). ${ }^{6}$ Since high costs was the main reason for not choosing the implant therapy, it is imperative to teach the patients that quality of life overshadows high cost of implants. The benefits and downside of all types of treatment modalities should be properly explained so they can make a learned choice.

Almost $100 \%$ of the participants in this survey were interested in having more information about dental implants. This outlines the yearning in people for education about implants.

\section{Conclusion}

The present study concluded that individual's knowledge and attitude towards implants was below average as an option for replacing missing teeth. It also shows that most individuals found dental implants treatment to be expensive and unaffordable but they were interested to know more about dental implants. The survey underlines the need for providing correct information through various means to the patients to improve awareness about this treatment modality

This study showed that young individuals in Ghaziabad have limited awareness about dental implants. It is also concluded that various efforts should be made to lower the cost of implants so that they can be made affordable to all who are in need of it.

\section{Conflict of Interest: None.}




\section{References}

1. Gbadebo OS, Lawal FB, Sulaiman AO, Ajayi DM Dental implant as an option for tooth replacement: the awareness of patients at a tertiary hospital in a developing country. Contemp Clin Dent 2014;5:302-06.

2. Omar R, Tashkandi E, Abduljabbar T, Abdullah MA, Akeel RF. Sentiments expressed in relation tooth loss: A qualitative study among edentulous Saudis. Int $J$ Prosthodont 2003;16:515-20.

3. Berge TI. Public awareness, information sources and evaluation of oral implant treatment in Norway. Clin Oral Implants Res 2000;11:401-08.

4. Tomruk C, Kayahan Z, Şençift K Patients' knowledge and awareness of dental implants in a Turkish subpopulation. J Adv Prosthodont 2014;6:133-37

5. Al-Johany S, Al Zoman HA, Al Juhaini M, Al Refeai M. Dental patients awareness and knowledge in using dental implants as an option in replacing missing teeth: A survey in Riyadh, Saudi Arabia. Saudi Dent J 2010;22:183-88.

6. Zimmer CM, Zimmer WM, Williams J, Liesener J (1991) Public awareness and acceptance of dental implants. Int $J$ Oral Maxillofac Implants 1991;7:228-32

7. Narayanan V, Karuppiah P, Rajasekar A, Mayavan D. Awareness among patients regarding dental implants as a treatment option for replacing missing teeth in Melmaruvathur population. IJOPRD 2016;6:6-9

8. Shah RJ, Chaturvedi A, Agarwal H. Dental implants as a treatment modality: Awareness survey among people in Ahmedabad. Int J Prosth Rest Dent 2014;4(2):35-38

9. Suprakash B, Ahammed AR, Thareja A, Kandaswamy R, Kumar N, Bhondwe $\mathrm{S}$ et al. Knowledge and attitude of patients towards dental implants as an option for replacement of missing teeth. J Contemp Dent Pract 2013;14(1):115-18.

10. Faramarzi M. Shirmohammadi A. Chisazi, MT. Kashefimehr, A. Farhoodi, E. Omrani A. Patient's Knowledge Regarding Dental Implants in Tabriz, Iran DJH 2012;4(1):33-8.

11. Tepper G, Haas R, Mailath G, Teller C, Zechner W Representative marketing-oriented study on implants in the Austrian population. I. Level of information, sources of information and need for patient information. Clin Oral Implants Res 2003;14:621-33

12. Pommer B, Zechner W, Watzak G, Ulm C, Watzek G, Tepper G. Progress and trends in patient's mindset on dental implants. I: level of information, sources of information and need for patient information. Clin Oral Implants Res 2011; 22(2):223-9.

13. Kohli S, Bhatia S, Kaur A, Rathakrihsnan T. Patients awareness and attitude towards dental implants. Indian $J$ Dent 2015;6:167-71

14. Suprakash B, AR Yusuf Ahammed, Thareja A, Kandaswamy R, Kumar N, Bhondwe S. et al. Knowledge and attitude of patients towards Dental Implant as an option for replacement of missing teeth. J Contemp Dent Pract 2013:14(1):115-18.

15. Berge TI. Public awareness, information sources and evaluation of oral implant treatment in Norway. Clin Oral Implants Res 2000;11(5):401-08

16. Best HA. Awareness and needs of dental implants by patients in New South Wales. Aust Prosthodont J 1993;7:9-12

17. Akagawa Y, Rachi Y, Matsumoto T, Tsuru H. Attitudes of removable denture patients toward dental implants. $J$ Prosthet Dent 1988;60(3):362-64.

18. Kaurani P, Kaurani M. Awareness of dental implants as a treatment modality amongst people residing in Jaipur (Rajasthan). J Clin Diagn Res 2010;4:3622-26.

19. Kent G. Effects of osseointegrated implants on psychological and social well-being: A literature review. J Prosthet Dent 1992;68(3):515-18

How to cite the article: Seth KG, Sharma B, Sharma N, Vaish S, Sethi M. Patient's knowledge and awareness towards dental implants in young individuals of Ghaziabad district- a cross sectional study. J Dent Specialities 2018;6(2):151-155. 